\title{
Assessment of Elements Altering Sleep Duration and Improving Quality of Life in Patients
}

\author{
Ishrar SMG, Narayana G, Pavani A, Ravi Ramudu D, B Sahithi \\ Department of Pharmacy Practice, Raghavendra Institute of Pharmaceutical Education and Research, Anantapuramu, \\ Andhra Pradesh, INDIA.
}

Received: 02 September 2018;

Accepted:08 November 2018

*Correspondence to:

Dr.Ishrar S.M.G,

Pharm. D,Assistant professor, Department of Pharmacy Practice, Raghavendra Institute of Pharmaceutical Education and Research (RIPER), Anantapuram, Andhra Pradesh, INDIA.

Phone no: +919000035936 Email:ID:ishrarpharma@gmail.com

Copyright: (C) the author(s),publisher and licensee Indian Academy of Pharmacists. This is an open-access article distributed under the terms of the Creative Commons Attribution Non-Commercial License, which permits unrestricted non-commercial use, distribution, and reproduction in any medium, provided the original work is properly cited.

\begin{abstract}
Background and Objectives: Sleep is a circadian, adaptive rhythm of inactivity. Alternations in sleep duration are due to irregular cycling or absent of sleep stages and circadian rhythms. The impact of sleep duration and sleep quality on health is widely recognized. It is important to assess and analyse the factors altering sleep duration in patients by conducting a clinical interview for evaluating the sleep quality. Methods: The study was conducted in all the departments except paediatric department of secondary referral hospital with sample size of 350 patients. The data collected from the patients through data collection form. Here SPSS/ANOVA statistics were used for data analysis and interpretation. Conclusion: From the obtained results, more than $92 \%$ of patients are suffering with sleep alteration that to more common reversible factors are altering sleep. Hence more awareness is required about sleep and sleep duration during different clinical conditions of patients as well as in normal persons. Sleep awareness can be provided by patient counselling to the patients during hospital stay to increase their quality of life.
\end{abstract}

Key words: Assess, Elements, Sleep duration, Patients.

\section{INTRODUCTION}

Sleep is a circadian, adaptive rhythm of inactivity. Sleep is a universal need of all higher forms including humans, absence of which has serious physiological consequences. ${ }^{[1]}$ Human spend about one-third of their lives asleep. An alteration in sleep duration is a common problem with a multi-factorial etiology in today's society. The impact of sleep duration and sleep quality on health is widely recognized. ${ }^{[2]}$ The association between sleep duration and a range of health outcomes has received growing attention. The normal duration of sleep in adults is $7-8 \mathrm{hrs}$ per night, ${ }^{[3]}$ although the timing, duration and internal structure of sleep vary among healthy individuals and as a function of age. Laboratory and epidemiological based evidence demonstrate that self-reported short and long duration are associated with morbidity and mortality conditions and poor self-rated health. ${ }^{[4]}$

Alterations in sleep duration are due to irregular cycling or absent of sleep stages and circadian rhythms. ${ }^{[5,6]}$ It is important to identify the factors altering the sleep duration in patients by patient reported health outcome measures which gives an opportunity in improving the quality of life in patients.

There is a growing body of research on sleep quality and sleep duration in hospitalized patients. Compared to previous studies, we studied a broader range of factors which could potentially affect sleep quality.

\section{MATERIALS AND METHODS}

A prospective observational study was performed for 6 months at RDT Hospital, Bathalapalli and Praja Vydhyasala, Anantapuramu. A structured process was followed for obtaining permission from hospital authority by submitting a detailed proforma of the study which includes protocol of the study, evidence of critically evaluated biomedical literatures, data collection form, patient informed consent form. After the initial acceptance from the hospital, study was registered in the IRB of the institution for ethical approval.

All the patients admitted in inpatient departments except paediatric department were eligible. Patients had to be 18 years or older and willing to participate in the study were included. We excluded those who were paediatric, mentally retarded, unconscious and coma. A data collection form was designed to collect the patient's information which was kept confidential, the information from patients were collected after obtaining their consent for which an informed consent form was designed separately.

\section{RESULTS}

During the study period, 350 participated in the study and provided their responses. Of these responses, 300 were screened and the rest 50 were excluded from the study because of incomplete information.

Demographic details of the participants involved in the study were categorized based on gender distribution, age distribution, smokers, alcoholic, smoking and alcoholic and the results were thoroughly analysed and reported in Table 1.

Predominant elements altering sleep rate in the patients who participated in the study were categorized and the results of which were analysed and reported in Table 2 .

\section{DISCUSSION}

We had confirmed, the sleep quality and duration is poor in the inpatients of our study. The results of the study shows that total of 11 factors were commonly expressed from all the patients involved in the study. Among the assessed factors, the most commonly sleep altering factors were pain $(64.67 \%)$, cough $(63.33 \%)$, frequent urination $(43 \%)$ and hospital 
Ishrar, et al.: Assessment of Elements Altering Sleep Duration

\begin{tabular}{|c|c|c|c|c|}
\hline \multirow{2}{*}{$\begin{array}{l}\text { SI.no } \\
1 .\end{array}$} & \multirow{2}{*}{$\begin{array}{l}\text { Demographic details } \\
\text { Gender Distribution }\end{array}$} & \multicolumn{3}{|c|}{ No. of participants } \\
\hline & & Male & Female & Total \\
\hline & Site 1 & 90 & 130 & 220 \\
\hline & Site 2 & 23 & 57 & 80 \\
\hline \multirow[t]{9}{*}{2.} & \multicolumn{2}{|l|}{ Age Distribution (years) } & & \\
\hline & $<18$ & 06 & 09 & 15 \\
\hline & $18-28$ & 10 & 18 & 28 \\
\hline & $28-38$ & 11 & 16 & 27 \\
\hline & $38-48$ & 13 & 28 & 41 \\
\hline & $48-58$ & 28 & 31 & 59 \\
\hline & $58-68$ & 24 & 43 & 67 \\
\hline & $68-78$ & 17 & 29 & 46 \\
\hline & $>78$ & 04 & 13 & 17 \\
\hline \multirow[t]{3}{*}{3.} & \multicolumn{4}{|l|}{ Social History } \\
\hline & Smokers & \multicolumn{3}{|c|}{$33(29.20 \%)$} \\
\hline & Alcoholic & \multicolumn{3}{|c|}{$18(15.92 \%)$} \\
\hline 4. & Smokers and alcoholics & \multicolumn{3}{|c|}{$26(23.00 \%)$} \\
\hline
\end{tabular}

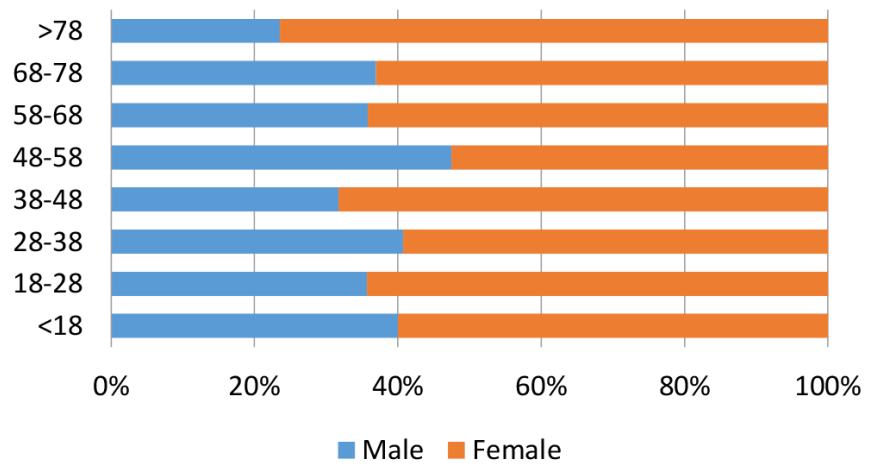

Figure 1: Age Distribution.

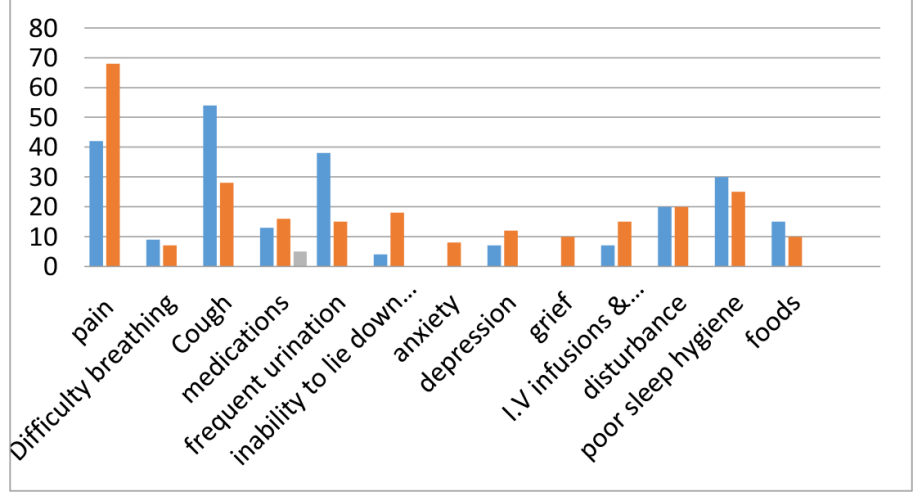

Figure 2: Elements altering sleep duration.

environment (41.6\%) which have high impact in altering sleep duration which are essential in mental and physically ill patients. In our study, $64.67 \%$ suffered from pain, similar findings were observed by Mohsen and Shintia et al..$^{7,8]}$

Table 2: Elements altering sleep rate in the patients $(n=300)$.

\begin{tabular}{|c|c|c|c|}
\hline \multirow{2}{*}{ SI.no } & \multirow{2}{*}{ FACTORS } & \multicolumn{2}{|c|}{ No. of Participants } \\
\hline & & Male n (\%) & Female n (\%) \\
\hline \multirow[t]{4}{*}{1.} & \multicolumn{3}{|l|}{ Medical/disease factors } \\
\hline & Pain & $42(37.16)$ & $68(36.36)$ \\
\hline & Difficulty breathing & $09(7.96)$ & $07(3.74)$ \\
\hline & Cough & $54(47.78)$ & $28(14.97)$ \\
\hline \multirow[t]{4}{*}{2.} & \multicolumn{3}{|l|}{ Psychological factors } \\
\hline & Anxiety & - & $08(4.27)$ \\
\hline & Depression & $07(6.19)$ & $12(9.62)$ \\
\hline & Grief & - & $10(5.34)$ \\
\hline \multirow[t]{3}{*}{3.} & \multicolumn{3}{|l|}{ Physical and posture related factors } \\
\hline & Frequent urination & $38(33.62)$ & $15(8.02)$ \\
\hline & Inability to lie down completely & $04(3.53)$ & $18(9.62)$ \\
\hline 4. & Medications/drug & $13(11.50)$ & $16(8.92)$ \\
\hline \multirow[t]{5}{*}{5.} & \multicolumn{3}{|l|}{ Hospital Environment } \\
\hline & Making room change & $02(1.76)$ & $06(3.20)$ \\
\hline & Poor sleep hygiene & $30(26.54)$ & $25(13.36)$ \\
\hline & Medical technical factors (ROA) & $07(6.19)$ & $15(8.02)$ \\
\hline & Disturbance (noise. Etc) & $20(17.69)$ & $20(10.69)$ \\
\hline 6. & $\begin{array}{l}\text { Diet related } \\
\text { (coffee and soda, Alcohol, Fatty } \\
\text { foods, water at night, high protein } \\
\text { diet) }\end{array}$ & $15(13.27)$ & $10(5.34)$ \\
\hline
\end{tabular}

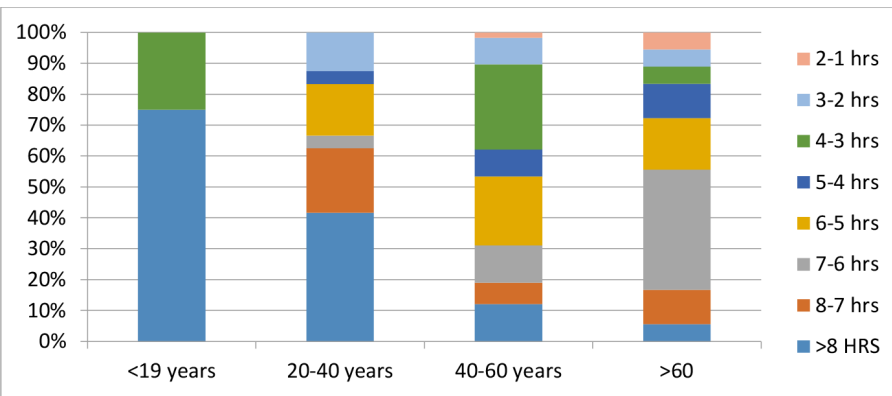

Figure 3: Sleep duration in patients before getting admitted into hospital.

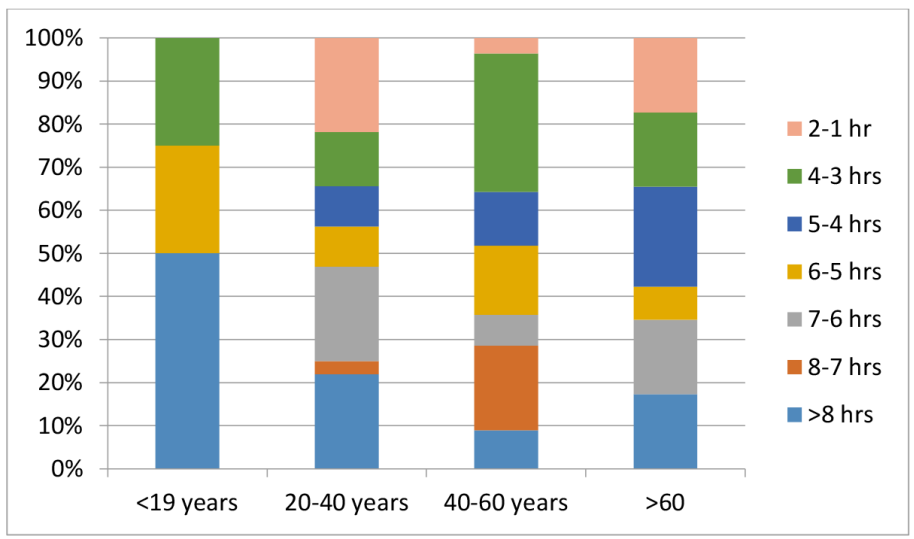

Figure 4: Sleep duration in patients during their hospital stay. 
Table 3: Sleep duration in patients before getting admitted into hospital.

\begin{tabular}{|c|c|c|c|c|c|c|c|c|}
\hline SI.no & $>8 \mathrm{hrs}$ & 8-7 hrs & 7-6 hrs & $6-5 \mathrm{hrs}$ & 5-4 hrs & 4-3 hrs & 3-2 hrs & 2-1 hrs \\
\hline$<19$ years & $3(75 \%)$ & 0 & 0 & 0 & 0 & $1(25 \%)$ & & 0 \\
\hline $20-40$ years & $10(11.36 \%)$ & $5(5.68 \%)$ & $1(1.14 \%)$ & $4(4.55 \%)$ & $1(1.14 \%)$ & 0 & $3(3.41 \%)$ & 0 \\
\hline $40-60$ years & $7(5.15 \%)$ & $4(2.94 \%)$ & $7(5.15 \%)$ & $13(9.55 \%)$ & $5(3.68 \%)$ & $16(11.76 \%)$ & $5(3.68 \%)$ & $1(0.74 \%)$ \\
\hline$>60$ years & $1(1.25 \%)$ & $2(2.5 \%)$ & $7(8.75 \%)$ & $3(3.78 \%)$ & $2(2.5 \%)$ & $1(1.25 \%)$ & $1(1.25 \%)$ & $1(1.25 \%)$ \\
\hline
\end{tabular}

\section{Table 4: Sleep duration in patients during their hospital stay.}

\begin{tabular}{|l|l|l|l|l|l|l|l|l|}
\hline SI.no & $\mathbf{>} \mathbf{h r s}$ & $\mathbf{8 - 7} \mathbf{h r s}$ & $\mathbf{7 - 6} \mathbf{h r s}$ & $\mathbf{6 - 5} \mathbf{h r s}$ & $\mathbf{5 - 4} \mathbf{h r s}$ & $\mathbf{4 - 3} \mathbf{h r s}$ & $\mathbf{3 - 2} \mathbf{h r s}$ & $\mathbf{2 - 1} \mathbf{h r}$ \\
\hline$<19$ years & $2(50 \%)$ & 0 & 0 & $1(25 \%)$ & 0 & $1(25 \%)$ & 0 \\
\hline $20-40$ years & $7(6.73 \%)$ & $1(0.96 \%)$ & $7(6.73 \%)$ & $3(2.88 \%)$ & $3(2.88 \%)$ & $4(3.85 \%)$ & $4(3.85 \%)$ & $7(6.73 \%)$ \\
\hline $40-60$ years & $5(3.68 \%)$ & $11(8.09 \%)$ & $4(2.94 \%)$ & $9(6.62 \%)$ & $7(5.15 \%)$ & $18(13.24 \%)$ & $9(6.62 \%)$ & $2(1.47 \%)$ \\
\hline$>60$ years & $2(3.73 \%)$ & 0 & $2(3.73 \%)$ & $1(1.67 \%)$ & $3(5 \%)$ & $2(3.7 \%)$ & $2(3.73 \%)$ & $2(3.73 \%)$ \\
\hline
\end{tabular}

The current study had shown $41.6 \%$ have altered sleep with hospital environment, similar findings were seen in somewhere else. ${ }^{[8-10]}$ Cough and frequent urination altered sleep in the patients of our study, similar findings were observed in Judith E. Carroll and Linda Gellerstedt. ${ }^{[11,12]}$

\section{CONCLUSION}

Sleep quality in inpatients is significantly worse in hospital than at home. 92\% of patients who were participated in the study, suffered with sleep alteration that to more common reversible factors altered the sleep.

The awareness about sleep and sleep duration was provided to patients by patient counselling during hospital stay in order to increase their quality of life and for promoting fast health recovery.

\section{ACKNOWLEDGEMENT}

The authors would like to thank the Principal, Medical Superintendents of Primary and Secondary Care Teaching Hospital, Bathalapalli, Anantapuramu, Andhra Pradesh for their constant support and guidance.

\section{CONFLICT OF INTEREST}

The authors declare no conflict of interest.

\section{ABBREVIATIONS}

None.

\section{REFERENCES}

1. Brain basics: Understanding Sleep. Office of communications and Public liaison, National Institute of Neurologic Disorders and Stroke, US National Institute of Health, Bethesda, MD. 2017.

2. Najib TA, David PW, JoAnn EM. A prospective study of sleep duration and coronary heart disease in women. Arch Intern Med. 2003;163(2):205-9.

3. Gottlieb DJ, Redline S, Nieto FJ, Baldwin CM, Anne BN. Association of usual sleep duration with hypertension: The sleep heart health study. Sleep. 2006;29(8):1009-14.

4. Dobing S, Frolova N, McAlister F, Ringrose J. Sleep quality and factors influencing selfreported sleep duration and quality in the general internal medicine inpatient population. PLoS ONE. 2016;11(6):e0156735.

5. Ayla U, Gokce D. Evaluation of sleep quality and fatigue in hospitalized patients. Int $J$ Caring Sci. 2012;5(3):311-9.

6. Seda P, Ayfer K, Yavuz P, Ahmet MO. Sleep quality and factors affecting sleep in patients with rheumatoid arthritis in Turkey. Turk J Med Sci. 2016;46(4):1114-21.

7. Elsayed MM, Magda AEM, Mamdouh MA, El-Tabaey SD Factors associated with sleep pattern disturbance among patients in Critical Care Units. IOSR J Nursing Healt Sci. 2015;4(2):54-63.

8. Shintia VDC, Maria FC. Factors that affect inpatients' quality of sleep, Rev Esc Enferm USP. 2013;47(1):46-52.

9. Sasmita D, Deepa OV, Jhunilata P, Sashmita K, Factors of sleep disturbances among hospitalized patients, jeopardizing the prognosis. Asian J Nursing Edu Res. 2015;5(2).

10. Bihari S, McEvoy RD, Kim S, Woodman RJ, Bersten AD. Factors affecting sleep quality of patients in Intensive Care Unit. J Clin Sleep Med. 2012;8(3):301-7.

11. Linda G, Jorgen M, Monica RK. Patients' experiences of sleep in hospital: A qualitative interview study. J Res Nursing. 2014;19(3):176-88.

12. Carroll JE, Irwin MR, Merkin SS, Seeman TE. Sleep and multisystem biological risk: A population based study. PLoS ONE. 2015;10(2):e0118467.

Cite this article as: Ishrar SMG, Narayana G, Pavani A, Ramudu RD. Assessment of Elements Altering Sleep Duration and Improving Quality of Life in Patients. J Pharm Pract Community Med. 2018;4(4):237-9. 